\title{
The application of experimental design models in order to optimize the synthesis of geopolymers
}

\author{
DimitrisKioupis, AggelikiSkaropoulou, Sotiris Tsivilis and GlikeriaKakali \\ National Technical University of Athens, School of Chemical Engineering, Athens, Greece
}

\begin{abstract}
The aim of this work is to propose the methodology and the mathematical tools for the design and development of geopolymeric materials from industrial wastes and by-products. The applied methodology follows the Taguchi fractional experimental design allowing the investigation of the combining effect of selected parameters in the response of the experimental system by conducting the minimum number of experiments. Two cases of geopolymer synthesis optimization based on the mechanical strength and the apparent density of the products, to which the Taguchi methodology has been successfully applied, are presented in the paper.
\end{abstract}

\section{Introduction}

An important part of global industrial production results in production of massive quantities of industrial byproducts or other solid wastes. In many cases, these materials contain hazardous compounds and their disposal poses a great social problem with environmental and health repercussions. The best way to handle the above solid waste is through recycling and reusing them into new products.

Recently, a new type of material, geopolymers or inorganic polymers [1], have significantly contributed to both the exploitation and reuse of aluminosilicate wastes and the development of new high added-value construction materials [2,3]. The geopolymer formation involves a chemical reaction between an aluminosilicate material and a silicate solution in an alkaline environment at ambient or slightly elevated temperature and leads to a construction material with rapid compressive strength development [4]. Geopolymers show similar, or even better, properties (mechanical, thermal, insulating, etc.) compared to conventional building materials, while they have minimal environmental impact and contribute to natural resources and energy savings [5]. Most importantly, depending on their design, such materials can exhibit attributes tailor made to the needs of the enduser.

The geopolymerization is a complicated process where the synthesis parameters possess a combined and co-dependent effect and thus their optimization is a difficult procedure. Factors, such as the curing conditions and the composition of the precursor, strongly affect the structure and properties of geopolymers [6-8].

The aim of this work is to suggest the methodology as well as the statistical tools to design and develop geopolymeric materials with a broad range of properties. The applied methodology follows the Taguchi experimental design model, which allows the investigation of the combined effect of selected parameters by conducting the minimum number of experiments [9-11]. In this study, the Taguchi approach was successfully applied in two cases of geopolymeric products development. The first case involves the fabrication of high strength building materials from brick waste while the second one concerns the development of lightweight geopolymer from fly ash with enhanced insulating capacity.

\section{Experimental Design: Taguchi Method}

The aim of a parameter design experiment is to identify and design the settingsof the process factors that optimize a chosen quality characteristic and are leastsensitive to noise (uncontrollable) factors. When many factors/inputs/variablesmust be taken into consideration, the Taguchi method is a structured approachfor determining the "best" combination of inputs to produce a product with optimizedproperties. The Taguchi method utilizes orthogonal arrays from design ofexperiments theory to study a large number of variables with a small number ofexperiments. Using orthogonal arrays significantly reduces the number of experimentalconfigurations to be studied. Furthermore, the conclusions drawn fromsmall scale experiments are valid over the entire experimental region.

The Taguchi experimental design belongs to the fractional factorial designs. In such designs, a simultaneous change of many factors is carried out systematically in order to ensure a reliable and 
independent study of the effects of the factors on the studied experimental system [12].

The Taguchi method involves the following steps: (i) definition of the problem to be solved, (ii) determination of the target performance of the process under consideration (quality characteristic), (iii) selection of the factors affecting the process and their value range, iv) design and conduction of the experiments, v) analysis of the data obtained from the experiments, vi) interpretation of the results and vii) verification experiments to confirm the results of the previous step.

The major advantage of the Taguchi method and of any fractional factorial design is that a significantly lower number of tests is required to fully describe the system, compared to a full factorial model. This results in a drastic reduction in both time and cost of the entire design. Table 1 shows a test group based on a fractional design.

Table 1.A test group of the Taguchi methodology $\left(\mathrm{L}_{9}\left(3^{3}\right)\right.$ orthogonal array).

\begin{tabular}{lccc}
\hline Test & Factor A & Factor B & Factor C \\
\hline $\mathbf{1}$ & 1 & 1 & 1 \\
$\mathbf{2}$ & 1 & 2 & 2 \\
$\mathbf{3}$ & 1 & 3 & 3 \\
$\mathbf{4}$ & 2 & 1 & 2 \\
$\mathbf{5}$ & 2 & 2 & 3 \\
$\mathbf{6}$ & 2 & 3 & 1 \\
$\mathbf{7}$ & 3 & 1 & 3 \\
$\mathbf{8}$ & 3 & 2 & 1 \\
$\mathbf{9}$ & 3 & 3 & 2 \\
\hline
\end{tabular}

An experimental system examined by the Taguchi method can be illustrated by means of orthogonal arrays (Table 1) [12]. These are basically tables where their columns correspond to the examined factors, while their rows to the factor levels for each experiment.

The orthogonal arrays are denoted by: $\boldsymbol{L}_{\boldsymbol{r}}\left(\boldsymbol{n}^{\boldsymbol{k}}\right)$, where the letter $\boldsymbol{L}$ is derived from the phrase Latin Squares, the $\boldsymbol{r}$ index is the number of lines, $\boldsymbol{k}$ is the number of the factors and $\boldsymbol{n}$ the number of factors levels. Generally, a large number of orthogonal arrays can be designed in order to meet the needs of the experiment. Table 2 shows some of the most commonly used orthogonal arrays. From Table 2, it is obvious that the selection of the Taguchi method drastically reduces the number of the tests in relation to the corresponding full factorial model.

Table 2.Commonly used orthogonal arrays.

\begin{tabular}{ccccc}
\hline $\begin{array}{c}\text { Orthogonal } \\
\text { array }\end{array}$ & $\begin{array}{c}\text { No. } \\
\text { tests }\end{array}$ & $\begin{array}{c}\text { No. } \\
\text { levels }\end{array}$ & $\begin{array}{c}\text { No. } \\
\text { factors }\end{array}$ & $\begin{array}{c}\text { No. tests } \\
\text { (full factorial } \\
\text { model) }\end{array}$ \\
\hline $\mathbf{L}_{\mathbf{4}}\left(\mathbf{2}^{\mathbf{3}}\right)$ & 4 & 2 & 3 & 8 \\
$\mathbf{L}_{\mathbf{8}}\left(\mathbf{2}^{\mathbf{7}}\right)$ & 8 & 2 & 7 & 128 \\
$\mathbf{L}_{\mathbf{1 2}}\left(\mathbf{2}^{\mathbf{1 1}}\right)$ & 12 & 2 & 11 & 2048 \\
$\mathbf{L}_{\mathbf{1 6}}\left(\mathbf{2}^{\mathbf{1 5}}\right)$ & 16 & 2 & 15 & 32768 \\
$\mathbf{L}_{\mathbf{3 2}}\left(\mathbf{2}^{\mathbf{3 1}}\right)$ & 32 & 2 & 31 & 2147483648 \\
$\mathbf{L}_{\mathbf{9}}\left(\mathbf{3}^{\mathbf{4}}\right)$ & 9 & 3 & 4 & 81 \\
\hline
\end{tabular}

\section{ANOVA analysis}

After the implementation of the Taguchi experimental model, the test results are statistically processed using the Analysis of Variance (ANOVA) [13]. The main goal of the ANOVA is to analyze the total dispersion observed in the values of the selected qualitative characteristic and to attribute it to the examined factors in order to derive their significance over the system. The total dispersion also includes the error (balance) which is defined as the random dispersion being present in the results if none of the examined factors affected them. In particular, random dispersion includes the experimental error, the effect of extra-experimental factors and experimental factors considered insignificant. The following relationship summarizes the basis of ANOVA analysis:

$\left(\begin{array}{c}\text { Total } \\ \text { Dispersion }\end{array}\right)=\sum_{k}\left(\begin{array}{c}\text { Dispersiondue } \\ \text { totheeffect } \\ \text { ofkfactor }\end{array}\right)+($ Balance $)$

In the ANOVA analysis, the significance of the testedfactors is calculated as the percent contribution of each factor to the selected qualitative characteristic of the process. The contribution of a factor to the system is significant when a change in its value causes a great effect on the response of the system. An appropriate statistical method called significance level is used to characterize the importance of the examined factors [10]. This method classifies the factors as significant or insignificant as to whether the dispersion caused by their variation is random or not.

Once the significant factors of the process have been identified, the optimal levels of the examined factors are calculated. For each factor, the value of the level closest to the desired response is considered as the optimal level. By setting the key factors at their optimum level, the response of the system can be predicted within a confidence interval.

The ANOVA analysis method ends by conducting verification experiments in order to establish whether the experimental design is successful and therefore the resulting conclusions are correct or not. To perform the verification experiments, the combination of the parameters optimizing the qualitative characteristic is selected and then a check if the results fall within the defined confidence interval takes place. If the results verify the predictions, it means that the optimal combination of factor-levels has actually been found and that the experimental system has been properly described. Otherwise, the design has failed to detect the effect of the factors and the system is being re-examined.

\section{Examplesof Synthesis Optimization}

Two examples of the geopolymer synthesis optimization, where the Taguchi method was successfully applied, are presented in the following paragraphs. Example 1 involves the development of geopolymers from brick waste exhibiting enhanced mechanical properties which can be used as alternative building materials. In the example 2 , the objective of the experimental design is to 
develop low density geopolymers utilizing fly ash from power plants which could find application as construction materials with enhanced insulating capacity.

A potential geopolymer precursor has to contain high amounts of amorphous $\mathrm{SiO}_{2}$ and $\mathrm{Al}_{2} \mathrm{O}_{3}$. Table 3 presents the chemical composition of the waste brick and fly ash used in the optimization examples as defined by XRF analysis. Both brick waste and fly ash contain considerable amounts of $\mathrm{SiO}_{2}$ and $\mathrm{Al}_{2} \mathrm{O}_{3}$ which are necessary for the geopolymerization.

Table 3. Chemical composition of the raw materials (\% w/w).

\begin{tabular}{|c|c|c|}
\hline Oxides & Brick waste & Fly ash \\
\hline $\mathrm{SiO}_{2}$ & 51.31 & 46.96 \\
\hline $\mathrm{Al}_{2} \mathrm{O}_{3}$ & 14.62 & 21.00 \\
\hline $\mathrm{Fe}_{2} \mathrm{O}_{3}$ & 8.45 & 9.83 \\
\hline $\mathrm{CaO}$ & 6.33 & 13.74 \\
\hline MgO & 8.10 & 2.20 \\
\hline $\mathrm{K}_{2} \mathrm{O}$ & 2.28 & 1.36 \\
\hline $\mathrm{Na}_{2} \mathrm{O}$ & 0.57 & 0.16 \\
\hline $\mathrm{SO}_{3}$ & 0.44 & 2.42 \\
\hline $\mathrm{TiO}_{2}$ & 0.66 & - \\
\hline $\mathrm{P} \mathrm{O}_{5}$ & 0.08 & - \\
\hline $\mathrm{Cl}$ & 0.04 & - \\
\hline L.O.I. & 39.7 & 1.94 \\
\hline
\end{tabular}

In order to define the factors (as well as their value ranges) which took place in the optimization of the synthesis, preliminary experiments conducted with the method of "changing one factor at a time" were performed in both approaches.

\subsection{Example 1: Achieving enhanced mechanical strength}

In the case of waste brick geopolymers, the performance of the examined system (geopolymer synthesis) was based on the compressive strength (quality characteristic) of the produced specimens. The synthetic factors which were investigated through the Taguchi methodology were the soluble silicon to alkali oxide $\left([\mathrm{Si}] / \mathrm{R}_{2} \mathrm{O}\right)$ molar ratio associated with the amount of dissolved $\mathrm{Si}$ in the activation solution, the alkali to aluminum (R/Al) molar ratio expressing the alkalinity of the activation solution and the $\mathrm{Na} /(\mathrm{Na}+\mathrm{K})$ ratio which is related to the kind of the alkali involved in the geopolymerization reaction. In order to illustrate the experimental design, the orthogonal array $\mathrm{L}_{9}\left(3^{3}\right)$ was chosen. This orthogonal array permits the examination of the three selected factors at three distinct levels (Table 4) and therefore reduces the number of the tests to 9 from 27 of the full factorial model. Compression tests were carried out on a Toni-technik uniaxial testing press, 7 days after the specimens' preparation (load rate $1.5 \mathrm{kN} / \mathrm{s}$, according to the EN196-1 requirements). Three specimens for each experiment were prepared andtested under compression.

Table 5 shows the set of the experiments designed by the Taguchi method along with the corresponding compressive strengths obtained after the tests. The values of the measurements are highly dispersed (2.3-36.4 $\mathrm{MPa}$ )indicating that the selected factors and their variation level have a significant effect on the target quality characteristic.

Table 4.Examined parameters and their variation levels (example 1).

\begin{tabular}{lccc}
\hline Factors & Level 1 & Level 2 & Level 3 \\
\hline$[\mathbf{S i}] / \mathbf{R}_{\mathbf{2}} \mathbf{O}$ & 0 & 1 & 2 \\
$(\mathbf{R} / \mathbf{A l})$ & 0.4 & 0.7 & 1.0 \\
$\mathbf{N a} /(\mathbf{N a}+\mathbf{K})$ & 0.0 & 0.5 & 1.0 \\
\hline
\end{tabular}

Table 5.Synthesis parameters and compressive strength of the produced geopolymers.

\begin{tabular}{lcccc}
\hline Test & {$[\mathbf{S i}] / \mathbf{R}_{\mathbf{2}} \mathbf{O}$} & $\mathbf{R} / \mathbf{A l}$ & $\mathbf{N a} / \mathbf{N a}+\mathbf{K}$ & $\begin{array}{c}\text { Compr. str. } \\
(\mathbf{M P a})\end{array}$ \\
\hline $\mathbf{1}$ & 0.0 & 0.40 & 0.00 & 2.32 \\
$\mathbf{2}$ & 0.0 & 0.70 & 0.50 & 14.4 \\
$\mathbf{3}$ & 0.0 & 1.00 & 1.00 & 12.3 \\
$\mathbf{4}$ & 1.0 & 0.40 & 0.50 & 14.5 \\
$\mathbf{5}$ & 1.0 & 0.70 & 1.00 & 24.5 \\
$\mathbf{6}$ & 1.0 & 1.00 & 0.00 & 36.4 \\
$\mathbf{7}$ & 2.0 & 0.40 & 1.00 & 6.0 \\
$\mathbf{8}$ & 2.0 & 0.70 & 0.00 & 8.7 \\
$\mathbf{9}$ & 2.0 & 1.00 & 0.50 & 33.3 \\
\hline
\end{tabular}

Figure 1 presents the results of the ANOVA statistical analysis by plotting the effect of the selected factors on the compressive strength of the produced samples. At the same time, Figure 1 shows the contribution of each factor in the system response as calculated by the significance level. The parameter with the greatest impact on the system is the R/Al molar ratio $(57.75 \%)$, followed by the $[\mathrm{Si}] / \mathrm{R}_{2} \mathrm{O}$ molar ratio with a contribution rate of $35.57 \%$. The kind of the alkali ion $(\mathrm{Na} / \mathrm{Na}+\mathrm{K})$ has only a marginal effect on the geopolymers properties $(6.68 \%)$.

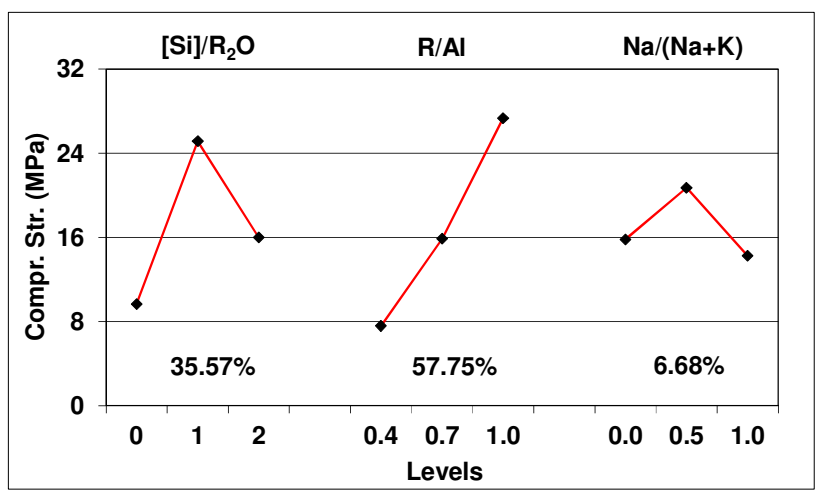

Fig 1. Graphic depiction of the ANOVA results (example 1).

The results analysis of the Taguchi multifactorial model showed that the optimal synthesis conditions for achieving the highest strength are: $[\mathrm{Si}] / \mathrm{R}_{2} \mathrm{O}=1.0$, $\mathrm{R} / \mathrm{Al}=1.0$ and $\mathrm{Na} /(\mathrm{Na}+\mathrm{K})=0.5$.

The optimized value of the compressive strength for a $95 \%$ confidence interval was predicted to be $39.4 \pm$ $4.8 \mathrm{MPa}$. In order to confirm the model prediction, geopolymer specimens with the optimal conditions were prepared, appropriately cured for 7 days and subjected to compression measurements. The compressive strength (mean of 3 specimens) was found to be $41.0 \mathrm{MPa}$ which falls within the predicting range, confirming in this way the validity of the used experimental design model. 


\subsection{Example 2: Achieving Reduced Density}

In the case of fly ash based geopolymers, the qualitative characteristic for the synthesis optimization is the apparent density of the produced specimens. In order to reduce the density of the products, foaming agent in the form of $\mathrm{Al}$ powder was introduced into the geopolymeric pastes. The factors selected to be investigated through the Taguchi method are: i) the foaming agent content (Al\%w/w on fly ash basis), ii) the alkali to aluminum molar ratio (R/Al, R: Na or K) which associates the alkali quantity in the activation solution with the aluminum content of the raw material and c) the $\mathrm{Na} / \mathrm{Na}+\mathrm{K}$ ratio which is related to the kind of alkali in the activation solution. The experimental design involved the variation of the above factors in four levels and so the $\mathrm{L}_{16}\left(4^{3}\right)$ orthogonal array was chosen to describe the experimental system. The apparent density was calculated as the average of three measurements. The variation levels of the selected factors are presented in Table 6.

Table 6.Examined parameters and their variation levels (example 2).

\begin{tabular}{lcccc}
\hline Factors & Level 1 & Level 2 & Level 3 & Level 4 \\
\hline Al \% w/w & 0.010 & 0.035 & 0.065 & 0.100 \\
R/Al & 0.8 & 1.2 & 1.6 & 2.0 \\
$\mathrm{Na} /(\mathrm{Na}+\mathrm{K})$ & 0.00 & 0.35 & 0.65 & 1.00 \\
\hline
\end{tabular}

The apparent density values along with the compressive strength of all the experimental design tests are shown in Table 7. As in the case of brick geopolymers, the system response exhibits a large dispersion of values $\left(0.64-1.56 \mathrm{~g} / \mathrm{cm}^{3}\right)$ indicating the correct selection of the selected factors as well as their value range.

Table 7.Synthesis parameters, apparent density and compressive strength of the produced geopolymers.

\begin{tabular}{lcccc}
\hline Test & $\begin{array}{c}\mathbf{A l} \\
(\mathbf{\%} / \mathbf{w})\end{array}$ & $\mathbf{R} / \mathbf{A l}$ & $\mathbf{N a} /(\mathbf{N a}+\mathbf{K})$ & $\begin{array}{c}\text { density } \\
\left(\mathbf{g} / \mathbf{c m}^{\mathbf{3}}\right)\end{array}$ \\
\hline $\mathbf{1}$ & 0.010 & 0.800 & 0.000 & 1.44 \\
$\mathbf{2}$ & 0.010 & 1.200 & 0.350 & 1.56 \\
$\mathbf{3}$ & 0.010 & 1.600 & 0.650 & 1.47 \\
$\mathbf{4}$ & 0.010 & 2.000 & 1.000 & 1.56 \\
$\mathbf{5}$ & 0.035 & 0.800 & 0.350 & 1.14 \\
$\mathbf{6}$ & 0.035 & 1.200 & 0.000 & 1.28 \\
$\mathbf{7}$ & 0.035 & 1.600 & 1.000 & 1.37 \\
$\mathbf{8}$ & 0.035 & 2.000 & 0.650 & 1.36 \\
$\mathbf{9}$ & 0.065 & 0.800 & 0.650 & 0.72 \\
$\mathbf{1 0}$ & 0.065 & 1.200 & 1.000 & 1.11 \\
$\mathbf{1 1}$ & 0.065 & 1.600 & 0.000 & 1.29 \\
$\mathbf{1 2}$ & 0.065 & 2.000 & 0.350 & 1.13 \\
$\mathbf{1 3}$ & 0.100 & 0.800 & 1.000 & 0.64 \\
$\mathbf{1 4}$ & 0.100 & 1.200 & 0.650 & 0.93 \\
$\mathbf{1 5}$ & 0.100 & 1.600 & 0.350 & 1.11 \\
$\mathbf{1 6}$ & 0.100 & 2.000 & 0.000 & 1.20 \\
\hline
\end{tabular}

Figure 2 shows the independent effect of the synthesis factors on the apparent density of the produced samples as derived from ANOVA analysis. The significance of each factor is expressed by the percent contribution to the qualitative target characteristic (apparent density). The most significant factor of theexamined system is the $\mathrm{Al} \% \mathrm{w} / \mathrm{w}$ content of the composition with a contribution of $66.31 \%$. The $\mathrm{R} / \mathrm{Al}$ molar ratio is the second most important factor $(26.58 \%)$, whereas the choice of alkali does not possess a significant effect on the apparent density of the produced geopolymers $(7.11 \%)$.

In summary, the analysis of the results showed that the delivery of a lightweight product is favored by the following parameter combination: $\mathrm{Al} 0.1 \% \mathrm{w} / \mathrm{w}$, $\mathrm{R} / \mathrm{Al}=0.80$ and $\mathrm{Na} /(\mathrm{Na}+\mathrm{K})=0.65$. In order to confirm the design model, a geopolymer with the above parameters was prepared. The apparent density was measured 0.65 $\mathrm{g} / \mathrm{cm}^{3}$ which falls within the range of predicted values $\left(0.66 \pm 0.05 \mathrm{~g} / \mathrm{cm}^{3}\right)$ for a $95 \%$ significance level.

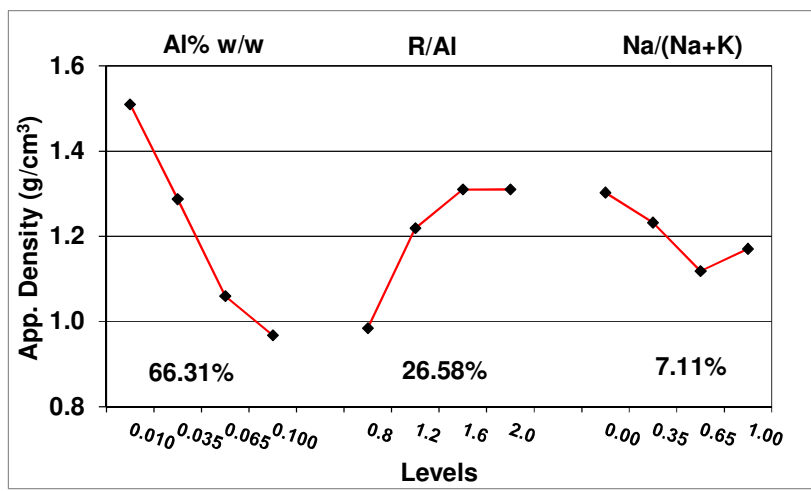

Fig. 2.Graphic depiction of the ANOVA results (example 2).

In order to assess the thermal behavior of the produced geopolymers, the thermal conductivity of the samples was measured. Figure 3 shows the apparent density and thermal conductivity values of the reference geopolymer $\left(55.5 \mathrm{MPa}\right.$ and $\left.1.77 \mathrm{~g} / \mathrm{cm}^{3}\right)$ and the optimal composition $\left(2.3 \mathrm{MPa}\right.$ and $\left.0.65 \mathrm{~g} / \mathrm{cm}^{3}\right)$ as derived from the experimental model. It is evident that the addition of metallic $\mathrm{Al}$ to the reactant components of the composition results in a drastic reduction in both density and thermal conductivity.

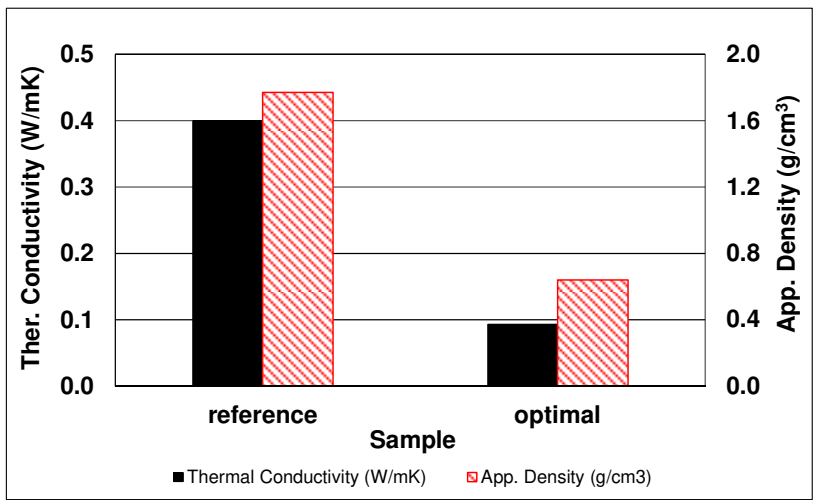

Fig. 3.Thermal conductivity and apparent density of the reference geopolymer and the optimum composition.

Typically, the reference geopolymer exhibits a conductivity value of $0.40 \mathrm{~W} / \mathrm{mK}$ while the optimal composition has a thermal conductivity value of almost one order of magnitude lower $(0.09 \mathrm{~W} / \mathrm{mK})$. The above results indicate the successful application of Taguchi fractional factorial design to the development of lightweight geopolymers with thermal insulating properties. 


\section{Conclusions}

In the present study, the application of the Taguchi multifactorial design of experiments is proposed in order to develop geopolymeric materials with desirable properties. In designing the experiment, it is important to define the desired target property (quality characteristic) on which synthesis optimization is based and to select the synthesis factors that have a significant effect on this property as well as their value range. Subsequently, experimental tests are determined by means of appropriate orthogonal arrays. The results of the tests are statistically processed with the help of ANOVA and the levels of the test factors optimizing the target property are determined. Finally, according to the optimum levels of the examined factors, the confirmation test is carried out which verifies or not the results of the analysis. The proposed methodology has been applied to the development of high-strength geopolymers from brick waste and lightweight geopolymersfrom fly ash, with successful results. The produced geopolymers showed compressive strength, density and thermal conductivity values in the range of 2-55 $\mathrm{MPa}, 0.6-2.0 \mathrm{~g} / \mathrm{cm}^{3}$ and $0.09-$ $0.40 \mathrm{~W} / \mathrm{mK}$, respectively.

\section{Acknowledgement}

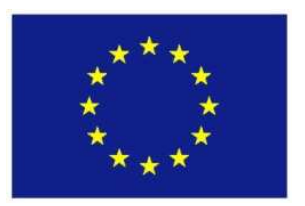

This project has received funding from the European Union's Horizon 2020 research and innovation programme under grant agreement No [723825].

\section{References}

1. J. Davidovits, J. Therm. Anal. 37, 1633 (1991)

2. J.L. Provis,Mater. Struct.47, 11 (2014)

3. J.L. Provis, A. Palomo, C. Shi,Cem. Concr. Res. 78, 110 (2015)

4. J.L. Provis, S.A. Bernal, Annu. Rev. Mater. Res. 44, 299 (2014)

5. B.Majidi, Mater. Tech. 24,79 (2009)

6. P.W. Ken, M.Ramli, C.C. Ban,Constr. Build. Mater.77, 370 (2015)

7. C. Panagiotopoulou, T. Perraki, S. Tsivilis, N. Skordaki, G. Kakali, Ceram. Eng. Sci. Proc. 29, 165 (2009)

8. C. Panagiotopoulou, A. Asprogerakas, G. Kakali, S. Tsivilis, Cer. Eng. Sci. Proc. 32,17-28 (2011).

9. C. Panagiotopoulou, S. Tsivilis, G. Kakali, Constr. Build. Mater. 91,17-22 (2015).

10. M.W. Weiser, K.B. Fong, Am. Ceram. Soc. Bul, 72, 87 (1993)

11. G. Taguchi, System of experimental design (Engineering Methods to optimize quality and minimize costs), (UNIPUB/ Kraus Int. Publications, New York, 1987)

12. T.B. Barker,Quality by experimental design,(Chapman \& Hall/CRC, 2005).

13. R.K. Roy,Design of experiments using the Taguchi approach, (John Wiley\& sons, New York, 2001) 